\title{
CLINICAL AND HISTOLOGICAL EVALUATION OF PATIENTS WITH BREAST DISEASES
}

\author{
Rajesh Chakkarapani1, Debarath Das ${ }^{2}$, Kishore Dhanajayan ${ }^{3}$
}

${ }_{1}^{1}$ Assistant Professor, Department of General Surgery, SRM Medical College Hospital and Research Centre, Kattankulathur. 2Postgraduate Student, Department of General Surgery, SRM Medical College Hospital and Research Centre, Kattankulathur. 3Postgraduate Student, Department of General Surgery, SRM Medical College Hospital and Research Centre, Kattankulathur.

\section{ABSTRACT}

\section{BACKGROUND}

Breast pathologies being benign and malignant with varying treatment options remain a challenge for the surgeons. Also, the prognosis of the breast disease varies from one condition to the other. With this varying treatment options and prognosis, breast diseases especially breast carcinomas add burden not only to the health care sector but also to the patient in economic terms also. Hence, this study was planned to know the clinical profile of breast diseases among females more than 15 years of age.

\section{MATERIALS AND METHODS}

Data was a descriptive study collected from hundred female patients above 15 yrs. of age who presented with breast lump, pain in the breast and nipple discharge and willing to undergo histopathology examination/ FNAC and treatment for their breast disease in outpatient and inpatient surgery department in SRM Medical College Hospital and Research Centre, Kattankulathur during the period from June 2013 to May 2016 were included as study subjects.

\section{RESULTS}

Majority of study participants (26) belonged to 31 - 40 years of age group. Breast lump and pain were the most common presenting symptoms. Clinically, 27 patients were diagnosed to have fibroadenoma and fibrocystic disease and abscess were reported in 14 patients and 8 patients, respectively. Also, 32 patients were clinically found to have carcinoma. Histopathologically, 30 patients were diagnosed to be suffering from ductal carcinoma. Fibrocystic disease was reported in 29 patients and fibroadenoma and mastitis in 23 patients and 9 patients, respectively.

\section{CONCLUSION}

This study shows that breast disease both benign and malignant were on increasing trends and this shows that health care sector needs to be strengthened in order to diagnose and treat breast diseases promptly and also further researches are needed.

\section{KEYWORDS}

Breast Diseases, Breast Carcinoma, Histopathology.

HOW TO CITE THIS ARTICLE: Chakkarapani R, Das D, Dhanajayan K. Clinical and histological evaluation of patients with breast diseases. J. Evolution Med. Dent. Sci. 2018;7(05):658-661, DOI: 10.14260/jemds/2018/149

\section{BACKGROUND}

Breasts are the secondary sexual characters in females. They are also the source of nutrition for the neonates and thus of mankind. They are also present in a rudimentary form in males. This tender, sensitive and delicate structure is constantly under the influence of hormones. The breast develops from mammary ridges. After menarche, the young virgin breast contains denser connective tissue. With progression in age, the dense breast becomes mixed glandular pattern tissue and with further progression in age breast begins to involute into fatty tissue.

Any aberration in this process leads to the susceptibility to a spectrum of localised pathologies like hyperplastic and neoplastic changes. Papilloma is a benign mass lesion that result from proliferation of the ductal epithelium that projects into the lumen of the duct. Papillomas may show areas of necrosis, haemorrhage and occasionally calcifications. Duct ectasia primarily affects the major ducts in

'Financial or Other Competing Interest': None.

Submission 20-12-2017, Peer Review 12-01-2018,

Acceptance 19-01-2018, Published 29-01-2018.

Corresponding Author:

Dr. Rajesh Chakkarapani,

No. 5/3, Muthu Street Krishnapuram,

Gingee-604202, Villupuram District.

E-mail:drrajesh83@gmail.com

DOI: $10.14260 / \mathrm{jemds} / 2018 / 149$

\section{(c) (i) $(9)$}

the subareolar region. These may be palpable or merely visible by mammography or ultrasound. Ductal hyperplasia can lead to Intraductal carcinoma. Fibroadenomas are benign solid tumours composed of stromal and epithelial elements. After carcinoma, fibroadenoma is the second most common tumour in the breast and is the most common tumour in women younger than 30 years. In contrast to cysts, fibroadenomas appear in teenage girls and women during their early reproductive years. They are rarely seen as new masses in women after the age of 40 or 45.

Breast cysts within the breast are fluid-filled, epitheliumlined cavities that may vary in size from microscopic to large palpable masses containing as much as 20 to $30 \mathrm{~mL}$ of fluid. A palpable cyst develops in at least 1 in every 14 women and $50 \%$ of cysts are multiple or recurrent. Adenosis refers to an increased number of small terminal ductules or acini. It is frequently associated with a proliferation of stromal tissue producing a histological lesion, sclerosing adenosis that can simulate carcinoma both grossly and histologically. Fibrocystic disease refers to greater than expected abundance of fibrous tissue and the formation of cysts. Fibrosis and cystic changes are extremely common in the breast. At autopsy as many as 50 percent of women have breast elements that can be termed fibrocystic.

Of the various pathologies that affect the breast, cancers are most often encountered and the most dreaded.1,2 Despite the gloomy prognosis, increased morbidity and reduced 
survival time, it can be controlled if common pathologies of the breast diseases were known. Thus, this study was planned to find the clinical profile of patients presenting with breast disorders.

\section{Objectives of the Study}

The objective of this study is to determine clinical and histological profile of breast diseases of females more than 15 years of age attending outpatient and inpatient Department of General Surgery in SRM Medical College Hospital and Research Centre, Kattankulathur during the period from June 2013 to May 2016.

\section{MATERIALS AND METHODS}

Data for this descriptive study was sourced from hundred female patients above 15 yrs. of age who presented with breast lump, pain in the breast and nipple discharge and willing to undergo mammogram, ultrasonogram and treatment for their breast disease in outpatient and inpatient surgery department in SRM Medical College Hospital and Research Centre, Kattankulathur during the period from June 2013 to May 2016 were included as study subjects. Patient with recurrent breast lumps and post-operative case of breast diseases were excluded. After taking the informed consent, data was collected by direct interview and detailed clinical history like past history, personal history, menstrual, obstetric and family history was taken. All the patients were subjected to clinical examination and clinical diagnosis was made as provisional diagnosis. All patients were examined regarding the character of the lump like size, shape, surface, borders, consistency, mobility, fixity to the breast, skin or chest wall. After examination of all 100 patients, the clinical diagnosis was made and then all patients were subjected to FNAC (Fine needle aspiration cytology) followed by excision biopsy in selected cases. Then the reports of FNAC/ Histopathological examinations were analysed.

\section{RESULTS}

In terms of age 15 patients were less than 20 years of age, 25 patients were between 21 - 30 years, 26 patients were between 31 - 40 years, 14 patients between 42 - 50 years and rest of the patients were above 50 years of age which is given in the table. It is evident from the table that fourth decade (31-40) showed the highest number of females with breast diseases. In the study, the youngest participant reported with breast is at 16 years of age and the oldest participant at 80 years of age. The age group wise distribution of patients is shown in Table 1.

\begin{tabular}{|c|c|c|}
\hline Age in Years & No. of Patients & Percentage (\%) \\
\hline $16-20$ & 15 & 15 \\
\hline $21-30$ & 25 & 25 \\
\hline $31-40$ & 26 & 26 \\
\hline $41-50$ & 14 & 14 \\
\hline $51-60$ & 12 & 12 \\
\hline $61-70$ & 7 & 7 \\
\hline $71-80$ & 1 & 1 \\
\hline Total & $\mathbf{1 0 0}$ & $\mathbf{1 0 0}$ \\
\hline \multicolumn{3}{|c|}{ Table 1. Age Distribution } \\
\hline
\end{tabular}

The patients presented with the symptoms suggestive of breast diseases like breast lump, pain in the breast and nipple discharge, and were included in the study. Of the total 100 patients, 48 patients presented with both lump and pain Lump and pain are the most common presenting symptoms of breast diseases in our study followed by 23 patients presented with pain alone and another 23 patients presented with lump alone. Six patients presented with nipple discharge which is associated with either lump or pain. In our study 46 patients presented with left breast involvement, whereas 42 patients presented with right breast involvement and 12 patients presented with bilateral breast symptoms. The clinical symptoms of all 100 patients are shown in Table 2 .

\begin{tabular}{|c|c|c|c|c|}
\hline Complaints & Right & Left & Bilateral & Total \\
\hline Lump & 6 & 16 & 1 & 23 \\
\hline Pain & 6 & 11 & 6 & 23 \\
\hline Lump + Pain & 27 & 16 & 5 & 48 \\
\hline $\begin{array}{c}\text { Lump + } \\
\text { Discharge }\end{array}$ & 0 & 3 & 0 & 3 \\
\hline $\begin{array}{c}\text { Lump + Pain + } \\
\text { Discharge }\end{array}$ & 3 & 0 & 0 & 3 \\
\hline Total & 42 & 46 & 12 & 100 \\
\hline \multicolumn{5}{|c|}{ Table 2. Clinical Symptoms } \\
\hline
\end{tabular}

In our study majority of the patients (65) had normal menstrual cycle, 27 patients were in postmenopausal age group and eight patients had cyclical mastalgia. All patients of cyclical mastalgia reported involvement of both breasts. The menstrual history of all 100 patients is shown in Figure 1.

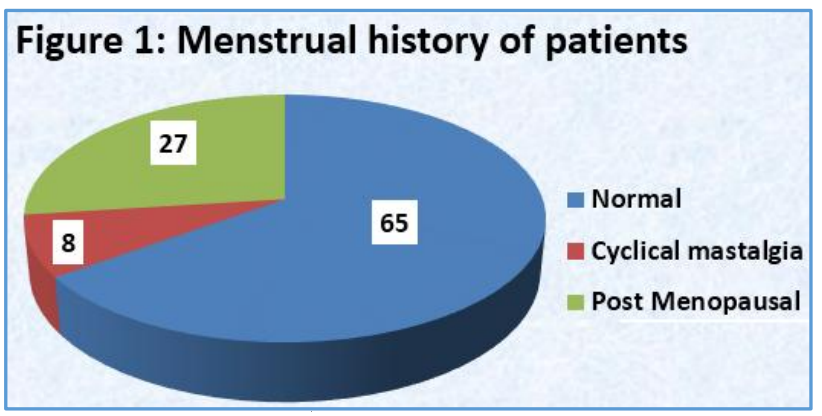

On clinical examination of all patients 77 patients had palpable lump, of which 33 patients reported involvement of upper outer quadrant, which is the most common location in this study followed by 29 patients, 11 patients and 4 patients reported involvement of subareolar, upper inner and lower outer quadrants, respectively. Seven patients had diffuse firm lump involving all quadrants. In this study, no patients had isolated lump in lower inner quadrant. On axillary examination, twelve patients had enlarged central group of lymph nodes due to axillary metastasis. Most of the patients who had axillary lymph nodes enlargement had lump in the upper outer quadrant. Five patients had circumferential retraction of nipple. The location of breast pathology of all 100 patients is shown in Table 3.

\begin{tabular}{|c|c|c|c|c|}
\hline Quadrants & Left & Right & Bilateral & Total \\
\hline Upper outer & 12 & 21 & - & 33 \\
\hline Upper inner & 11 & - & - & 11 \\
\hline Lower outer & - & 4 & - & 4 \\
\hline Lower inner & - & - & - & - \\
\hline Subareolar & 18 & 9 & 2 & 29 \\
\hline All quadrants & - & 7 & - & 7 \\
\hline \multicolumn{6}{|c|}{ Table 3. Breast Lesions- Side and Quadrants }
\end{tabular}


After examination of all 100 patients, the clinical diagnosis was made. In the study 27 patients were clinically diagnosed to have fibroadenoma, the most common benign breast disease reported in this study. Also other benign lesions like fibrocystic disease and abscess were reported in 14 patients and 8 patients, respectively. Antibioma, galactocoele and simple cysts were reported in one patient, each. In our study 32 patients were clinically found to have carcinoma, which occupies the largest proportion of all breast diseases. The clinical diagnosis of all 100 patients is shown in Table 4.

\begin{tabular}{|c|c|}
\hline Clinical Diagnosis & No. of Patients \\
\hline Abscess & 8 \\
\hline Antibioma & 1 \\
\hline Carcinoma & 32 \\
\hline Cyst & 1 \\
\hline Fibrocystic disease & 14 \\
\hline Fibroadenoma & 27 \\
\hline Galactocele & 1 \\
\hline Normal & 16 \\
\hline \multicolumn{2}{|c|}{ Total } \\
\multicolumn{2}{|c|}{ Table 4. Clinical Diagnosis } \\
\hline \multicolumn{2}{|c|}{}
\end{tabular}

All patients after clinical examination were subjected to necessary investigations and then finally diagnosis was confirmed by FNAC (Fine needle aspiration cytology)/ Histopathological examination (after surgery). In our study out of 100 patients who reported with breast symptoms, 93 were diagnosed to have breast diseases and all of them were subjected to FNAC followed by excision biopsy (selective cases). 30 patients were diagnosed to be suffering from Ductal Carcinoma, which is the most common disease reported in this study. Among the benign diseases of the breast, fibrocystic disease was reported in 29 patients which is the most common benign breast disease found in this study followed by fibroadenoma and mastitis in 23 patients and 9 patients, respectively. Galactocele and lactational adenoma was reported in one patient each. Also 7 patients were reported to be normal. Overall benign lesions are more common than the malignant breast lesions. The histopathological diagnosis of the 100 patients with symptoms of breast disease is shown in Table 5.

\begin{tabular}{|c|c|}
\hline Diagnosis & HPE \\
\hline Fibroadenoma & 23 \\
\hline Ductal carcinoma & 30 \\
\hline Fibrocystic disease & 29 \\
\hline Galactocele & 1 \\
\hline Lactational adenoma & 1 \\
\hline Mastitis & 9 \\
\hline Normal & 7 \\
\hline Total & 100 \\
\hline \multicolumn{2}{|c|}{ Table 5. FNAC/Histopathological Diagnosis } \\
\hline
\end{tabular}

\section{DISCUSSION}

\section{Pathophysiology of Breast Diseases}

The mammary glands arise along the milk lines that extend along the anterior surface of the body from the axilla to the groin. During puberty, pituitary and ovarian hormonal influences stimulate female breast enlargement, primarily owing to accumulation of adipocytes. Each breast contains approximately 15 - 25 glandular units known as breast lobules, which are demarcated by Cooper ligaments. Each lobule is composed of a tubuloalveolar gland and adipose tissue. Each lobule drains into the lactiferous duct, which subsequently empties onto the surface of the nipple. Multiple lactiferous ducts converge to form one ampulla, which traverses the nipple to open at the apex. ${ }^{3}$ Below the nipple surface, lactiferous ducts form large dilations called lactiferous sinuses, which act as milk reservoirs during lactation. ${ }^{4}$

When the lactiferous duct lining undergoes epidermalisation, keratin production may cause plugging of the duct resulting in abscess formation.5,6 This may explain the high recurrence rate (an estimated 39\% - 50\%) of breast abscesses in patients treated with standard incision and drainage, as this technique does not address the basic mechanism by which breast abscesses are thought to occur.

Breast masses can involve any of the tissues that make up the breast including overlying skin, ducts, lobules and connective tissues. Fibrocystic disease, the most common breast mass in women, is found in $60 \%-90 \%$ of breasts during routine autopsy. Fibroadenoma, the most common benign tumour typically affects women younger than 30 years and accounts for $91 \%$ of all solid breast masses in females younger than 19 years. ${ }^{3}$ Infiltrating ductal carcinoma is the most common malignant tumour; however, inflammatory carcinoma is the most aggressive and carries the worst prognosis.

\section{Age and Breast Diseases}

Fibroadenoma, one of the benign pathologies, is the most common cause of breast mass in women younger than 35 years. ${ }^{3}$ Women who were aged 40 years or older account for more than $95 \%$ of new breast cancer diagnoses and $97 \%$ of breast cancer deaths and the median age at breast cancer diagnosis is 61 years. Also breast infections, most commonly affect women aged 18 - 50 years. ${ }^{7}$

\section{Clinical Presentation and Breast Diseases}

Ryerson et $\mathrm{al}^{8}$ reported pain or tenderness (49.3\%) as the most common presenting symptoms of breast diseases followed by breast lump, which is common among $31.7 \%$ patients with breast diseases, whereas Karia et al ${ }^{9}$ reported breast lump as the common symptom (91.7\% patients) followed by breast pain (23.1\% patients).

\section{Menstrual History and Breast Diseases}

Women, who attain menarche, younger than 12 years of age were at higher risk of breast cancer later in their life time.10 The same is true for women who go through menopause when they are older than 55 . Over the past 15 years, girls have been starting puberty at younger ages. Breast development has started even earlier than menstrual periods. This unexpected shift has been attributed to the obesity epidemic and broad exposure to hormone disruptors since rise in hormones trigger the onset of breast development and puberty. The age when women go through menopause, however, has stayed about the same. Terry et al ${ }^{11}$ reported longer menstrual cycles at ages 18 to 22 years were associated with a lower incidence of premenopausal breast cancer before age 40, whereas irregular cycles at ages 18 to 22 years or in early adulthood were not associated with reduced premenopausal breast cancer risk. 


\section{Histopathological Findings of Breast Diseases}

Carcinoma of breast showing a significant increase in the incidence and cancer-associated morbidity and mortality in Indian subcontinent as described in global and Indian studies.12-14 Earlier cervical cancer was most common cancer in Indian women, but now the incidence of breast cancer has surpassed cervical cancer and is a leading cause of cancer death, although cervical cancer still remains most common in rural India. ${ }^{15}$

Regarding benign breast diseases, Conrad et al ${ }^{16}$ in New York reported fibroadenoma as the common benign breast disease and it was found among $45 \%$ of patients followed by mastitis reported among $17 \%$ of the patients. Mastitis is usually seen in lactating women, but the presence in a nonlactating woman should spur evaluation for an inflammatory carcinoma, newly onset diabetes, infection with Mycobacterium tuberculosis, and other idiopathic causes. 17 Lactational mastitis is seen in approximately $2 \%-3 \%$ of lactating women ${ }^{18}$ and breast abscess may develop in $5 \%$ $11 \%$ of women with mastitis. ${ }^{19}$

\section{CONCLUSION}

In this study, based on the histopathological examination, benign breast diseases were more common than the malignant breast diseases. As the benign lesion is associated with malignant breast disease in later age, it is must to pick the breast diseases at an earlier stage and treat it. Also, with the view of increasing burden of the breast pathologies, it is necessary to understand about the breast disease in detail by conducting large scale studies.

\section{REFERENCES}

[1] Clarke D, Sudhakaran N, Gateley CA. Replace fine needle aspiration cytology with automated core biopsy in the triple assessment of breast cancer. Ann R Coll Surg Engl 2001;83(2):110-12.

[2] Schoonjans JM, Brem RF. Fourteen-gauge ultrasonographically guided large-core needle biopsy of breast masses. J Ultrasound Med 2001;20(9):96772.

[3] Kaneda HJ, Mack J, Kasales CJ, et al. Pediatric and adolescent breast masses: a review of pathophysiology, imaging, diagnosis and treatment. AJR Am J Roentgenol 2013;200(2):W204-12.

[4] Whitaker-Worth DL, Carlone V, Susser WS, et al. Dermatologic diseases of the breast and nipple. J Am Acad Dermatol 2000;43(5 Pt 1):733-51; quiz 752-4.
[5] Bland KI, Copeland EM. The breast: comprehensive management of benign and malignant disorders. 3rd edn. Saunders 2004.

[6] Kasales CJ, Han B, Smith JS, et al. Nonpuerperal mastitis and subareolar abscess of the breast. AJR Am J Roentgenol 2014;202(2):W133-9.

[7] Dixon JM. Breast infection. BMJ 2013;347:f3291.

[8] Ryerson AB, Miller J, Eheman CR. Reported breast symptoms in the National Breast and Cervical Cancer Early Detection Program. Cancer Causes \& Control 2015;26(5):733-40.

[9] Karia JB, Kothari MD, Palekar HD, et al. Clinical features and pattern of presentation of breast diseases in surgical outpatient clinic of a tertiary hospital. Pain 2014;28:23-1.

[10] Breast cancer organization. Menstrual history. http://www.breastcancer.org/risk/factors/menstrua l_hist

[11] Terry KL, Willett WC, Rich-Edwards JW, et al. Menstrual cycle characteristics and incidence of premenopausal breast cancer. Cancer Epidemiology \& Biomarkers Prevention 2005;14(6):1509-13.

[12] Porter PL. Global trends in breast cancer incidence and mortality. Salud Publica de Mexico 2009;51(Suppl 2):S141-S6.

[13] Reddy SK, Shah B, Varghese C, et al. Responding to the threat of chronic diseases in India. Lancet 2005;366(9498):1744-9.

[14] Balasubramaniam SM, Rotti SB, Vivekanandam S. Risk factors of female breast carcinoma: a case control study at Puducherry. Indian J Cancer 2013;50(1):6570.

[15] Kaarthigeyan K. Cervical cancer in India and HPV vaccination. Indian $\mathrm{J}$ Med Paediatr Oncol 2012;33(1):7-12.

[16] Schuerch C, Rosen PP, Hirota T, et al. A pathologic study of benign breast diseases in Tokyo and New York. Cancer 1982;50(9):1899-903.

[17] Sheybani F, Sarvghad M, Naderi HR, et al. Treatment for and clinical characteristics of granulomatous mastitis. Obstet Gynecol 2015;125(4):801-7.

[18] Mass S. Breast pain: engorgement, nipple pain and mastitis. Clin Obstet Gynecol 2004;47(3):676-82.

[19] Lam E, Chan T, Wiseman SM. Breast abscess: evidence based management recommendations. Expert Rev Anti Infect Ther 2014;12(7):753-62. 